\section{EMBRYAIDDLE \\ Aeronautical University}

SCHOLARLY COMMONS

\section{International Journal of Aviation,} Aeronautics, and Aerospace

\title{
Managing Safety Risks in Airline Maintenance Outsourcing
}

\author{
Rajee Olaganathan Dr. \\ Rajee Olaganathan, olaganar@erau.edu \\ Mark Miller Dr. \\ Embry-Riddle Aeronautical University, millmark@erau.edu \\ Bettina M. Mrusek Dr. \\ Embry-Riddle Aeronautical University, mrusekb@erau.edu
}

Follow this and additional works at: https://commons.erau.edu/ijaaa

Part of the Aviation Safety and Security Commons

\section{Scholarly Commons Citation}

Olaganathan, R., Miller, M., \& Mrusek, B. M. (2020). Managing Safety Risks in Airline Maintenance Outsourcing. International Journal of Aviation, Aeronautics, and Aerospace, 7(1). https://doi.org/ 10.15394/ijaaa.2020.1435

This Article is brought to you for free and open access by the Journals at Scholarly Commons. It has been accepted for inclusion in International Journal of Aviation, Aeronautics, and Aerospace by an authorized administrator of Scholarly Commons. For more information, please contact commons@erau.edu. 


\section{Managing Safety Risks in Airline Maintenance Outsourcing}

Due to the Civil Aeronautics Act of 1938, the aviation industry in the US faced less competition for nearly 40 years i.e., between 1938 and 1978. Aircraft maintenance is an important and necessary task that is required to maintain the airworthiness of the aircraft, ensuring it is safe for operation. Before deregulation, the airlines normally carried out the maintenance tasks in-house, but this trend later changed. Two developments that occurred in the aviation industry led to the shift from in-house maintenance to outsourcing. The first is the airline deregulation act (1978) which removed the barriers and paved way for the expansion of the aviation industry. As a result, low-cost carriers (LCC) entered the market. This was largely due to the fact that maintenance personnel in large legacy carriers were unionized. This was very costly to maintain once the low-cost carriers like Southwest Airlines started competing against them. To compete in this market both LCC and legacy airlines started partially outsourcing the maintenance work. This allowed carriers to focus on customer service and the growth of their businesses. The second development was the introduction of non-stop international routes. As the network of intercontinental airlines proliferated, the requirement for regular maintenance in foreign countries increased. This resulted in the development of maintenance, repair, and overhaul (MRO) operations worldwide which was later approved by the Federal Aviation Administration (FAA) (Ridge Global, 2018). Outsourcing phase maintenance which would be costly to perform in house due to lab or unions could now be outsourced to cheaper, non-unionized labor in foreign countries. This would seem to be a good business practice overall as long as quality standards are maintained.

To ensure safety and for the successful operation of an aircraft, maintenance work is essential and hence is highly regulated by several authorities both at the national and international level. The European Aviation Safety Agency (EASA) in Europe, the FAA (United States), and many other countries have their own aviation authorities (Regattieri, Giazzi, Gamberi, \& Gamberini, 2015). Due to the strict regulations set by the authorities' and limited resources, airlines outsourced maintenance work partially to MRO organizations that have the required facilities (Al-Kaabi, Potter, \& Naim, 2007).

The U.S. aviation industry faced severe financial losses after the 9/11 incident. The financial loss that occurred between 2000 and 2009 in the U.S. alone was $\$ 54$ billion dollars (Philips, 2011). As previously stated, one of the operational strategies adopted by the air carriers (LCC and legacy carriers) to overcome this hurdle was to outsource aircraft maintenance. This allowed airlines to reduce their capital investment in hanger facilities, equipment, parts, and component purchase, as well as labor costs (Tang \& Elias, 2012). As a result, the trend of outsourcing maintenance works increased tremendously throughout the aviation industry. In 1996 , only $37 \%$ of the maintenance work was outsourced which accounted for USD 
$\$ 1.5$ billion. This increased to $64 \%$ accounting for approximately USD 3.7 billion in 2009 (Office of Inspector General [OIG], 2009). As the outsourcing and offshoring of aircraft maintenance work increased, concerns about the safety implications of such work became the subject of debate. This paper will further analyse this problem by reviewing the global aviation maintenance outsourcing market, related risk factors, and resulting safety issues.

\section{Research Method}

To determine the effect of outsourcing aircraft maintenance and inspection work on safety, an online literature search was carried out the Hunt Library of Embry Riddle Aeronautical University and Web of Science. The search was limited to articles that are published between 1990 and 2018. The keywords used either individually or in combination with the literature search were: outsourcing maintenance, maintenance error, inspection errors, accidents, risk factors, and regulations. Based on the literature examined, this paper will discuss the concept of outsourcing and the trend of aviation outsourcing at a global level, related risk factors, including the analysis of aviation accidents (the US and abroad) that occurred due to a maintenance failure, the relationship to outsourcing, and the regulatory steps taken by the FAA and other concerned authorities as a result. An analysis of the recent developments in MRO industry will also be included. Finally, recommendations to minimize the risks associated with maintenance outsourcing will be provided in an effort to further contribute to literature on the safety implications of outsourcing aircraft maintenance.

To identify and analyze the business model for outsourcing aviation maintenance, a Strengths, Weaknesses, Opportunities, and Threats (SWOT) analysis was also used. This model helps to identify the external and internal threats that affect positives and negatives in achieving the goal (Helms \& Nixon, 2010). Strengths are the factors that give an advantage over the others while weakness is those factors that affect negatives. Opportunities are the chances/factors that a business could exploit for its growth, and threats are the factors that could adversely affect the business. The results of SWOT analysis are discussed in "Industrial Analysis and Challenges of Outsourcing Maintenance."

\section{Literature Review: Global Outsourcing of U.S. Aircraft Maintenance}

\section{Global MRO Market based on the Areas of Maintenance}

Outsourced maintenance work can be classified into four major areas: airframe maintenance, engine maintenance, component maintenance, and line maintenance. While there are other areas that can be outsourced, these categories will serve as the focus areas for this research paper. The outsourcing of aircraft maintenance work is flourishing. Maintenance work outsourced by the major carriers was 37\% in 1996 and has increased to 64\% in 2009 (OIG, 2009). The 
outsourcing of heavy airframe maintenance was $34 \%$ in 2003 and it almost doubled to $71 \%$ in 2007 . Out of this, $27 \%$ of the maintenance work was provided by foreign repair stations (OIG, 2009). Another research study revealed that the market share of heavy maintenance cost was $22 \%$, engine maintenance cost was $42 \%$, while component and line maintenance cost remained at the rate of $19 \%$ and $18 \%$ ) respectively in 2015 (Doan, 2015). The same study forecasted that the market share of heavy maintenance will be $17 \%$, engine maintenance will increase to $47 \%$ and the market share of the component and line maintenance cost will be the same by 2025 (Doan, 2015).

Czepiel (2003) reported that the revenue of the MRO market worldwide was 30 billion USD and forecasted that the growth would be $4.3 \%$ by 2018 . Figure 1 illustrates that the total revenue spent on global MRO on the line maintenance, component maintenance, engine maintenance, and heavy maintenance from 2002 to 2010 was approximately $\$ 360$ billion USD. By 2020, the world MRO spending is projected to increase to $\$ 65$ billion, which is roughly double compared to the spending of 2003 (Czepiel, 2003).

Oliver Wyman, a leading global management consulting firm, reported that in 2018 total MRO spending is anticipated to be $\$ 77.4$ billion (2018). Over a fiveyear period, it is forecasted to increase at a rate of 3.5\% Compound Annual Growth Rate (CAGR) accounting for $\$ 91.9$ billion by 2023 . Over the full 10 -year period, it is expected to increase by four percent annually, accounting for $\$ 114.7$ billion by 2028 (Cooper, Smiley, Porter, \& Precourt, 2018). 


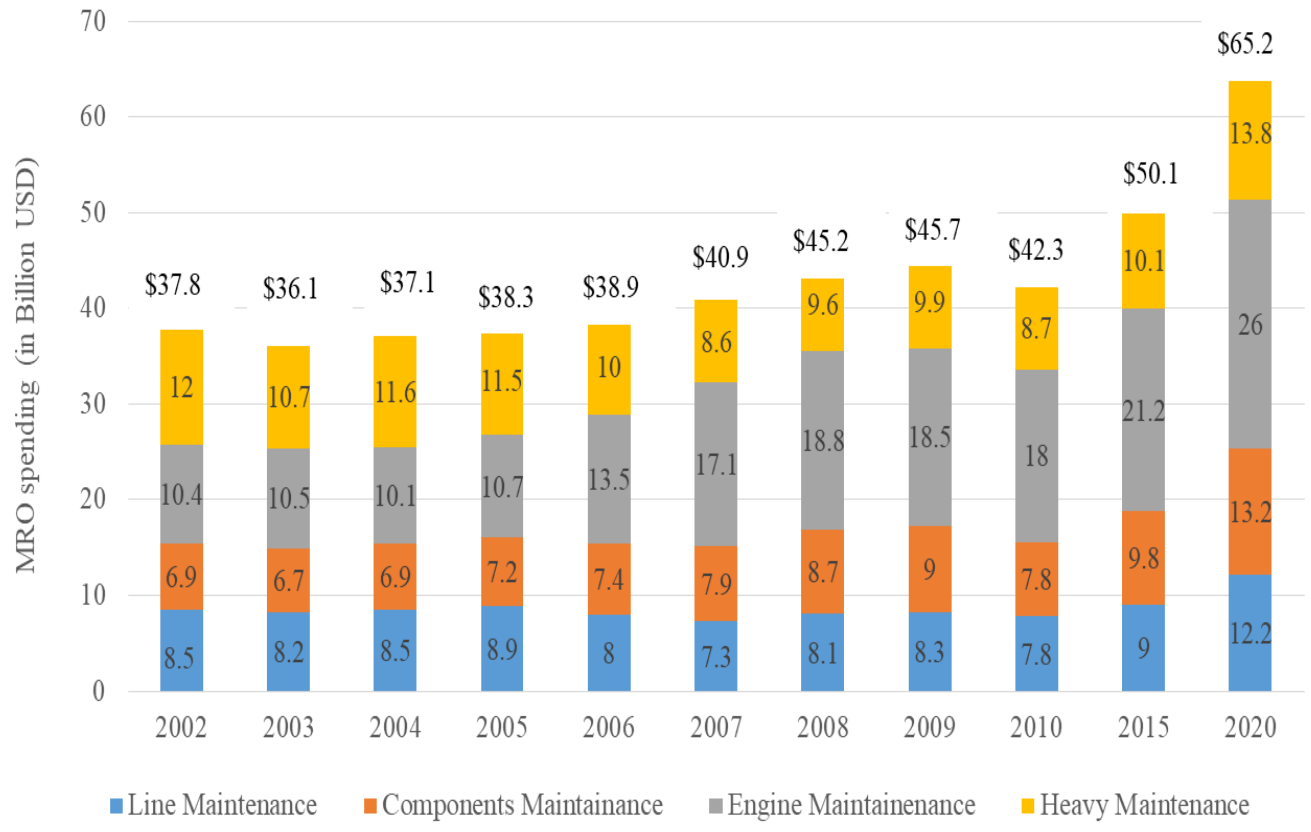

Figure 1. Estimated MRO spending at the global level. Adopted from Aviation Week/Overhaul and Maintenance April Issue 2010 (as cited in "Airline maintenance costs executive commentary," 2011, International Air Transport Association, p. 3). Copyright 2010

In their research, Cooper et al. (2018) noted that the MRO market is driven mainly by the heavy maintenance. Though the engines are fuel efficient and they operate at high pressure and temperatures, the parts have to be replaced frequently and hence its market share is expected to grow by $4.9 \%$ annually. In case of the line and component maintenance, there will be little change (Cooper et al., 2018). The shift to new generation aircraft will undoubtedly result with additional challenges for line and component maintenance sector. In case of line maintenance, the major issues for the service organization will be training their personnel, investing and utilizing the new software configuration protocols, using the fault isolation systems, and aircraft health monitoring system. With regard to component maintenance, the organization will require more capital investment to purchase the testing equipment and licenses to access the data and original equipment manufacturers manual (Cooper et al., 2018). Regionally, as fleet growth shifts to Asia and other developing economies, MRO spending will also migrate to those regions. The combined demand for MRO in the Asia Pacific, China, and India will be twice as that in North America by 2028. 


\section{Regional Market Share of MRO}

As the largest MRO market, North America accounted for $\$ 15.6$ billion of the industry in 2007 compared to $\$ 10.4$ billion in Western Europe, $\$ 5.6$ billion in Asia-Pacific, \$2.3 billion in China, \$2 billion in Middle East and South America, $\$ 1.5$ billion in Africa, $\$ 1.2$ billion in Eastern Europe, and \$444 million in India (McFadden \& Worrells, 2012). The projected demand for air travel is also higher in Asia-Pacific than in other countries, which will notably influence market share. As fleet growths shift towards developing countries, the MRO market will also grow in those regions. Cooper et al. (2018) projected that when the MRO market share from Asia-Pacific, China, and India are combined it will be more than double the market share of North America by 2028.

The MRO share of North America in 2018 was expected to be $\$ 19.4$ billion, while the market in Latin America is expected to increase and reach $\$ 6.2$ billion by 2028. The European market is expected to increase as well. Western Europe is expected to increase by three percent per year and reach $\$ 21.7$ billion by 2028 . With a $4.3 \%$ annual growth rate, the Middle East MRO is expected to contribute $12 \%$ by 2028 , with the African market will retaining the same growth rate. India is expected to grow by 5.6 percent per year, with China growing $10.6 \%$ per year. Given projected growth rates, Asia will be a significant contributor to the MRO market (Cooper et al., 2018).

Though China is the primary contributor in Asia, limitations with regard to the infrastructure, capacity and increasing cost of labor may force Chinese air carriers to send their fleet to southern and eastern regions to ensure maintenance work is completed on time (Doan, 2015). Currently, 24\% of heavy airframe maintenance work of wide-body fleets are outsourced to China, but due to the projected growth of the region, the Asia MRO market cannot meet its own demand along with the outsourced work. Hence, they have to find an alternate provider. Such opportunities could be shifted to America, and Europe in the future (Cooper et al., 2018).

\section{Risk Associated with Outsourcing and Off-shoring}

MRO organizations are incredibly complex; efficient operations require substantial expertise and risk. Some of the internal challenges include the lack of the adequate staff and trained personnel, non-availability of the required parts of the aircraft, inefficiencies in workload scheduling, operating processes, and deficiencies in the work environment related to ergonomics (which can pose a serious threat to safety). Some MROs have limited or no access to the internet and unreliable communication facilities which can also impact its successful operation. Additionally, some foreign MROs are located in remote places which limits the ability of local civil aviation authorities (CAA), and the Federal Aviation Administration (FAA) inspectors to validate whether the maintenance works are carried out as per the specified procedures (International Civil Aviation 
Organization [ICAO], 2016). The COSCAP (Cooperative Development of Operational Safety and Continuing Airworthiness Program) of International Civil Aviation Organization (ICAO) has urged the sharing of information between the civil aviation authorities so that MROs know which areas are expected to be inspected by local CAA authorities FAA inspectors, as well as personnel from the air carrier. The FAA also provides guidance to its inspectors about the MROs and the area to be inspected. Ultimately the expectations of the standards in these locations are often subjective and based on the individual inspector (ICAO, 2016). ICAO being an advisory body encourages and advises MROs about lack of consistent standards, but it does not have the authority to enforce it. Aviation maintenance organizations within the US have quality insurance programs. These quality programs create a system of safety checks and balances within the maintenance organization to ensure safety. Maintenance organizations outside the US lack these quality programs and as a result, it is difficult to maintain the quality of work. Often times, the lower the cost of the outsourcing, the lower the chance of the presence of these critical check and balance programs.

Cyber risk also poses a serious threat to safety, especially in the electronic documentation and transmission of reports, documents, and personal records. These transmissions must be done accurately and in a reliable way otherwise, it compromises the secure and efficient operation of MROs. It can also affect the tracking and monitoring of the documented progress related to the rectification of identified issues. If MROs cannot secure information technology resources, inspection records, and qualification documentation, it could affect the accuracy of these records, which are primarily used to determine whether MROs are in compliance with stated (ICAO, 2016). Another potential barrier is the effective language communication between these organizations. Though FAA regulations require supervisors working at foreign MROs to understand, write, and read in English, it also allows individuals to become FAA-certified mechanics even if they don't meet the language requirement (ICAO, 2016).

Regarding regulatory risks, differences in the requirement for domestic and foreign repair stations play a significant role. All FAA-approved stations must comply with Part 145 requirements. The Advisory Circular (AC) 120-16E describes how a maintenance organization should be set up for both a FAR Part 121 and Part 135 operations (McFadden \& Worrells, 2012). The management perspective behind the FAA certified Part 145 repair station is that it will provide superior maintenance, and play a significant role in reducing accidents, mishaps, and enhancing safety. The guidance material and tools highlight functional requirements, design expectations, and performance objectives. Contrarily, these repair stations were responsible for maintenance errors that led to several mishaps.

Another area of concern is the suspected unapproved parts used by MROs. The FAA has issued multiple advisory circulars which provide information about 
identifying the replacement parts and provide guidelines for the inspection of parts received in order to confirm its authenticity. Due to the large number of vendors and MROs involved, it is difficult for FAA to monitor whether the parts have been manufactured with FAA approval which poses a significant risk to the safety of the aircraft. To combat this problem, the FAA issued Advisory Circular (AC) 120-92 B which outlines the requirements for Safety Management System (SMS) program. It contains information about the four components of SMS systems namely Safety Policy, Safety Risk Management, Safety Assurance, and Safety Promotion for air carriers and aviation service providers such as Non-Part 121 Operators, MROs, and training organizations (FAA, 2015). If implemented properly, SMS programs can minimize the challenges related to communication, oversight, and suspected unapproved parts. Essentially, the four components work together to form a comprehensive safety management program that identifies, addresses, and communicates potential hazards in the workplace. The following section will discuss the accidents that occurred due to the of maintenance work, further justifying the need for effective safety management programs.

\section{Outsourcing and Related Accidents}

Several accidents that occurred in 1995 revealed that the root cause was found to be outsourced aircraft maintenance work. The ValuJet DC 9 (Flight 597) flight from Atlanta, Georgia to Miami, Florida which departed on 8 June 1995 is a prime example. During its take-off, there was an uncontained engine failure which caused a fire. The failure was due to the fatigue-related crack in the 7th disc of high compressor disc of the engine. The NTSB (National Transportation Safety Board) investigation found that the cause was the inaccurate inspection of a 7 th stage high compressor disk which was carried out by the maintenance personnel of Turk Hava Yollari repair station of Turkey (NTSB, 1996). This caused the crack to expand and rupture which forced the engine fragments into the fuselage which in turn cut off the fuel line of the right engine and caused a fire. The NTSB also stated that the lack of an adequate record keeping system for the repair station and the failure to use "process sheets" to document the step-by-step inspection procedures contributed to the non-detection of the crack which led to the accident (NTSB, 1996). Another ValuJet DC -9 (Flight 592) crash that occurred in 1996 led to a national debate about FAA's ability to provide adequate supervision over these repair stations. SabreTech, the maintenance service provider of ValuJet, failed to properly prepare, pack and identify unexpended chemical oxygen generators. ValuJet failed to oversee its contract maintenance provider to ensure it was in compliance with FAA regulations. The accident investigation report concluded that SabreTech was responsible for this accident (General Accounting Office, 1997).

In a China Airlines flight, a Boeing 737, on a scheduled flight from Taiwan to Japan landed in the Okinawa airport. After taxiing to a gate, it caught fire. Fortunately, everyone on board escaped without serious injury. The Japan 
Transport Safety Board (JTSB) investigation team reported that during the maintenance work that was carried out in Taiwan, the mechanics failed to attach a washer which is part of the right-wing assembly. This later became loose and punctured a fuel tank which caused the fire (JTSB, 2009). During the same year, US Airways flight 518, on a scheduled flight from Omaha to Phoenix, made an emergency landing at Denver as the seal around the cabin door failed. The NTSB investigation revealed that the mechanic at Aeroman's El Salvador station (maintenance service provider of US Airways) fixed a component of the door improperly, installing it backward (Zwerdling, 2009).

In 2010, a Boeing 747, an Air France aircraft, went through a major maintenance inspection at a facility in China. It was later grounded when it was found that the exterior of the aircraft was refinished with flammable paint (Steele, 2015). Another example was a series of Air France flights in which an A340 aircraft went through a major overhaul at Taeco-Taikoo Aircraft Engineering Co. Ltd., an MRO facility in Xiamen, China. Approximately 30 screws were missing from a protective panel which was unnoticed by the mechanics and ground crew. It left the facility and had a stop at Roissy for three days, where it remained unnoticed by the ground crew. Overall, it flew with 30 missing screws for five days until landing in Boston, where it was identified and grounded (Rothman, 2011).

In 2019, Lion Air Flight 610, a Boeing 737 MAX 8 on a domestic flight scheduled from Jakarta Soekarno-Hatta International Airport to Pangkal Pinang crashed into the Java Sea twelve minutes after its departure. This was one of the deadliest accidents in the Boeing MAX series. All the passengers and flight crew on board died. The preliminary investigation discovered that the crash occurred due to the failure of the Angle of Attack (AOA) sensor as well as other instrument failures. The investigation team linked it to the design flaw of MAX series and following the crash of an Ethiopian Airlines Flight 302 on March 2019, all Boeing 737 MAX aircraft were grounded worldwide. The Indonesian investigation team recently revealed that the aircraft that crashed on October 2018 was repaired in a maintenance facility in the US. The AOA sensor that was involved in the crash did not work from the time it was installed. It went through maintenance at repair station XTRA Aerospace Inc. in Miramar, Florida. FAA, the Indonesian investigation team, and Boeing are currently examining the work that was carried out at this repair station (Levin \& Suhartono, 2019).

\section{Federal Regulations}

\section{Regulatory Oversight and Actions Taken by FAA}

All FAA approved repair stations must comply with FAR Part 145 rules. But there are dissimilarities in the rules that form the regulatory differences between domestic and foreign repair stations, i.e., in some cases, the rules are stringent for U.S. based stations and in others, it is stricter for foreign stations. The 
most prominent differences are: foreign stations must renew their certificates every two years whereas the certificate issued for U.S. based MROs do not expire. For supervisory rules, U.S. based MROs should employ only FAA-certified mechanics, but foreign repair stations do not have this requirement. Additionally, there is no FAA mandated alcohol and drug testing for the staff at foreign MROs while it is mandatory for U.S. MROs (Government Accountability Office [GAO], 2016). Though the requirements are less strict for foreign MROs, these organizations must adhere to both Part 145 and the local civil aviation authorities in that specific region. The FAA not only authorizes the regulations, but based on regular inspections, audits, incident and accident investigation reports it also issues advisory circulars and airworthiness directives to ensure the airworthiness of the aircraft for its safe operations.

SMS is a systematic process of identifying risks, analyzing them, and taking decisive actions to accept, reduce, or eliminate those risks. From an aviation maintenance organization's perspective, SMS refers to the steps and/or processes that assist in identifying the errors that might occur while working on an aircraft. According to ICAO's SMS framework, approved maintenance organizations that provide service to aircraft, and helicopters are required to implement SMS programs (ICAO, 2013). ICAO suggests a four-stage approach to implement SMS programs over a five-year period. The FAA is now encouraging MROs to implement an SMS programs to manage safety by including the necessary organizational structures, accountability practices, policies, and procedures. While the development of a fully-effective SMS program is a multi-year project, it is believed that organizations that update their safety programs early will see benefits much more quickly. Moreover, from a practical perspective it can be difficult to implement SMS in all countries that are providing MRO services. The FAA is encouraging MROs to implement SMS, but has not mandated that they do so. If SMS implementation is mandated for MROs, the safety mishaps could be reduced significantly. The FAA has noted that a positive, proactive relationship with product/service providers is preferable to an adversarial, legalistic approach of providing effective safety oversight.

\section{Treaties and Agreements}

The regulatory agencies located in foreign countries play a significant role with regard to the oversight of maintenance on U.S. aircraft. FAA has a bilateral aviation agreement with 48 countries. These agreements reduce the workload and facilitate the oversight of maintenance stations. These agreements "provide streamlined systems of demonstrating compliance with applicable regulations without compromising safety. But as the 2015 GAO report demonstrates, bilateral agreements can present an added risk if procedures for providing adequate ongoing oversight are not in place" (Ridge Global., 2018, p. 15). 


\section{Role of Airlines}

Airlines conduct inspections of the MROs and review their performance before assigning the contracts. Even after assigning the contract, airlines conduct regular inspections, audits, and oversee the maintenance program on a continuous basis to ensure the standards of safety mentioned in the contract. The effectiveness of airlines oversight of maintenance program is inspected by FAA on a regular basis (Tang \& Elias, 2012).

\section{Role of Manufacturers (engine and airframe)}

The manufacturers (airframe, engine, and component) have a regulatory responsibility to provide information regarding how to maintain their products to assure that it can be operated safely. Both airframe and engine manufacturers have entered in the MRO industry by establishing MRO networks at a global level and this is described briefly in the recent development in MRO section below.

\section{Discrepancies Related to FAA's Oversight of Maintenance Program of Airlines}

The FAA is also responsible for overseeing the maintenance program to ensure the airworthiness of the aircraft. As required by 14 CFR part 121, $\$ 121.367$, and part $135, \S 135.425$, the air carrier's maintenance program must ensure that all of its aircraft released to service are airworthy, well maintained for safe operation, and that everyone who works with on the aircraft follow maintenance program requirements (FAA, 2016). Though the FAA requires this, errors do occur. For example, in 2008, the Office of Inspector General received a complaint against American Airlines (AA), one of the largest and safest air carriers. This complaint included 10 maintenance-related charges including the failure of the cockpit windshield installation in three of its flights, an unacceptable level of maintenance delays, inspections that were carried out by non-qualified personnel, and the failure to conduct inspections as per the manufacturer's service bulletin (OIG, 2010). The complaint also questioned the effectiveness of FAA's oversight over the air carrier's maintenance program. Due to the seriousness of the complaint, OIG conducted an audit (June 2008 - December 2009). The audit results confirmed that AA's maintenance program lacked rigidity in identifying the errors and associated safety implications of its current maintenance practices. The FAA tracked the number of delays, but failed to track which type of aircraft parts caused the delays. So, the opportunity to identify the potential maintenance issues, and to take the corrective action was missed. The NTSB found that AA's CASS (Continuing Analysis and Surveillance System) system was not effective, and that it failed to detect the repeated maintenance discrepancies. Additionally, the FAA did not perform the routine surveillance of AA's CASS and reliability programs (OIG, 2010). The OIG audit also confirmed that AA did not implement Boeing's service bulletin (OIG, 2010). 
FAA AC 120-16G provides excellent guidance in preparing the Maintenance program. Having a maintenance program alone does not ensure the safety of the airlines. It must be implemented effectively. In 2015, 42 of Allegiant's aircraft broke down in mid-flight. Among that, 15 aircraft were forced to land due to engine failure, nine overheating tail components, and either smoke or the burning smell. Allegiant fleet's average age was 12 years and they required the most rigorous maintenance in the industry. The FAA inspection revealed that there were issues related to maintenance paperwork (Lash, Levesque, \& Cormier, 2016). Recently, the OIG received a complaint that questioned the effectiveness of the FAA's oversight over the air carrier's maintenance program. Due to the seriousness of the maintenance issues, OIG is conducting an audit on FAA's oversight especially with American Airlines and Allegiant Airlines (Josephs, 2018). The audit aims to investigate whether FAA ensures that both the airlines have implemented the suggested corrective actions to address the root cause of the maintenance issues.

\section{Regulatory Actions Taken by FAA}

Though there is sufficient legislation, at times organizations prioritize profitability higher than other operational elements, such as safety. The balance between safety and efficiency in aviation has historically been difficult to maintain, especially in times of financial strain. When organizations choose not to comply with regulations, the FAA is keen to respond, but non-compliance still occurs in the industry. In 2010, FAA declared that American Airlines did not follow the steps outlined in a 2006 Airworthiness Directive (AD). This AD required operators to inspect the wire bundles located in the wheel wells of MD-80 aircraft. The AD 2006-15-15 required a one-time general visual inspection by March 2008 and the purpose was to prevent the shorting of wires at the auxiliary hydraulic pump, which could result in loss of hydraulic power or a fire in the wheel well of the aircraft. It required operators to perform corrective actions in accordance with the instructions of the applicable manufacturer's service bulletin. It also aimed to reduce the chance of an ignition close to the fuel tanks, which could result in a fuel tank explosion. But American Airlines did not fix the problems as per the deadline. As American Airlines violated the AD, FAA imposed a fine of $\$ 24.2$ million. This was the highest fine imposed by FAA in the industry (Crawley, 2010).

The recent AD issued by FAA was based on the engine failure aboard Southwest Airlines Flight 1380. The NTSB investigation revealed that engine failure occurred as the fan blade broke from a crack near the fan's hub. This failure was similar to one that occurred on another Southwest flight in September 2016. The report stated that "At the hub... there's a fatigue fracture where this \#13 fan blade would come into that hub. It also fractured roughly halfway through it. But it appears the fatigue fracture was the initial event. We have the root part, but we don't have the outboard part. The crack was interior, so certainly not detectable from 
looking at it from the outside" (Gallagher, 2018, para. 2). After this incident, CFM International, the engine manufacturer issued a technical bulletin and insisted that the customers should conduct more frequent ultrasonic inspections of the fan in the type of turbofan engine used by Southwest's 737 Next Generation aircraft. In 2017, CFM requested FAA to enact a new rule regarding the engine inspection (14 CFR Part 39 - Docket No. FAA-2016-9592; Directorate Identifier 2016-NE-30-AD; Amendment 39-18952; AD 2017-14-08). Shockingly, SWA opposed this AD stating that there are 732 engines in SWA and more time will be required to schedule and complete the ultrasonic inspections. FAA has not taken any final decisions on this yet.

\section{Industrial Analysis and Challenges of Outsourcing Maintenance}

The expansion in commercial aviation business from 2019 to 2029 should be supported by the MRO market as well. Airlines usually outsource the MRO service to a repair shop, a system supplier or, more recently, to an aircraft OEM to reduce its operating costs. The total MRO market is expected to increase to $\$ 116$ billion by 2029 (Cooper, Reagan, Porter, \& Precourt, 2019). Business for the MROs in the initial five years from 2019 to 2024 is estimated to be $\$ 19$ billion, and this slow growth is attributed to the newer aircraft that enter the fleet. The average growth is predicted to be $3.5 \%$ over the next decade, especially between 2024 and 2029 (Cooper et al., 2019). Due to this potential growth, it is essential to understand the strengths, weaknesses, opportunities, and threats of the outsourcing maintenance business. The following section are the results of the SWOT analysis that was completed, based on the perspective of aircraft OEM, system suppliers, repair shops, and airlines.

\section{SWOT analysis for Aircraft Original Equipment Manufacturers}

Aircraft Original Equipment Manufacturers such as Airbus, Boeing, Bombardier, Embraer, and others have contracts with system suppliers. An OEM confronts the twin challenges of the cost structure in the country of operations and culture as it competes with aggressive, and experienced local pure MRO suppliers. This is one reason a company must become more agile, and reduce long decision cycles. The strength of aircraft OEM is their consolidated customer relationship, but their weakness lies in the fact that they are focused only on the production and not on the aftermarket business opportunities that are available after production, and sales. Moreover, to exploit this opportunity they may require high capital investments to set up MRO service stations without which they cannot acquire this growing market. At the same time, OEMs may become more aggressive on pricing or charges for customer support activities that are currently given away for free which is another major weakness for OEM. However, if successful, they have the opportunity to build partnerships with suppliers and small companies in other countries to develop their own MRO services. Finally, they are threatened by 
political instability, and fluctuating currency exchange rates of the country where they want to establish MRO services.

\section{SWOT for System Suppliers}

From a system supplier's perspective, they supply the system and parts to both the OEMs and OEMs competitors. Their strength is as they are the primary system suppliers and have extensive knowledge of the systems. They can easily get the contracts from OEMs for the aftermarket business, but they have restrictions related to the type of systems they manufacture. This is their main weakness. System distribution is a scale-intensive activity in which a bigger network is generally better. Compared to smaller companies and repair shops, they have opportunities to build partnerships with OEMs to expand the MRO service much easier. The threat in the system supplier's perspective is that both OEM and airlines are entering the MRO business.

\section{SWOT for Repair Shops}

The main strength from a repair shops perspective is that they already know the market, and have the required expertise to repair the system and parts. Their weakness is that most do not undertake any heavy maintenance works. Based on their specialization, they have more opportunities to build partnerships with other companies in MRO service. The threat to repair shops is high from their competitors as there are several repair shops around the world.

\section{SWOT for Airlines}

Airlines can build their own MRO service to do their work and for providing service to other airlines. It will be more beneficial as they have a strong and large knowledge base, but their inflexible structure would be their weakness, which should be rectified to exploit this business opportunity. There are a lot of opportunities as they can utilize both expertise, and capacity to expand and focus on new markets. The fluctuating demands, the adaption of new technology in the industry, and entry of OEMs into the market are the threats they have to consider in this industry.

The strengths, weaknesses, opportunities, and threats (SWOT) analysis of the outsourcing maintenance based on different stakeholder's perspective shows there is strong competition within this market segment. There are several system suppliers, and repair shops who are building partnerships with OEMs to expand their market. The most important fact in this industry is customer satisfaction. Today's customers are demanding a "one-stop solution" as time is more important, and this situation is affecting the small maintenance companies. To be in the business they have to define their unique differentiating benefits.

\section{Recent Developments in the MRO Industry}

Aircraft maintenance is a highly regulated, safety critical, and complex industry which is facing exceptional challenges. Expected growth rates further 
complicate this scenario. To maintain this growth and capitalize on the new opportunities, MRO organizations have to position themselves accurately in the market. One of the best ways to do so is to develop global partnerships with reliable suppliers, logistics, and technology providers. These strategic global collaborations have proven to be beneficial. Technology partnerships help to manage MRO processes and supply chain, incorporating the use of augmented reality to train mechanics, and partnerships which bring together the expertise and workforce of existing MROs to further expand the capacity of MROs (Grokhovskaya, 2018, a).

AAR, a U.S.-based MRO organization, has recently joined with the Airbus MRO Alliance to become a preferred provider of heavy maintenance to Airbus customers is currently planning on opening a new MRO in India. ST Aerospace (Singapore) is working closely with the OEMs and recently made an agreement with Airbus to provide airframe heavy maintenance and modification services. StandardAero, an independent MRO has grown rapidly (Adams, 2017). In 2017 it acquired PAS Technologies, Jet Aviation Specialists, and Vector Aerospace and its revenue is growing to about $\$ 3$ billion. The company now have 42 locations globally. HEICO, on the other hand, is increasing its revenues through acquisitions. HEICO Repair Group is one of the largest independent component MROs, servicing and shipping more than 60,000 units/year. Boeing Global Services (BGS) has developed a partnership with Air France KLM on 737 and 777 programs, and Boeing Shanghai, has a joint venture with China Eastern, and Boeing Asia Pacific Services, has a joint venture with SIA Engineering Co. Boeing also has a joint venture with Air India in India. Lufthansa Technik Component Services has started its operation in Tulsa, Oklahoma. Airbus MRO Alliance has signed agreements with MROs like AAR, Aeroman, Sabena Technics, Etihad Airways Engineering, GAMECO, and China Airlines to optimize heavy maintenance turnaround times (Adams, 2017). HNA Technic in China has more than 30 maintenance bases in China, 10 regional centers, and a service network of over 200 stations worldwide. HNA group has partnerships/collaborations with different organizations which include carriers such as Hainan Airlines and MROs such as HNA Technic (China), myTECHNIC (Turkey), and SR Technics (Switzerland). These global partnerships are also established by the engine manufacturers. GE Aviation and Lufthansa Technik have a long-term material service agreement. GE also maintains an extensive MRO network outside the U.S. especially in Asia and Europe. As a joint venture, Pratt \& Whitney and Turkish Technic together started Turkish Engine Center (TEC) in Istanbul for engine MRO (Adams, 2017).

Besides solid partnerships, MROs must also be responsive to the evolving aircraft designs, changes to durable parts, new schedules of maintenance, and more efficient engines (Grokhovskaya, 2018a). Technological advancements also play a significant role in the MRO industry. For example, Aircraft Communications Addressing and Reporting System (ACARS) was developed in 1978 by 
Aeronautical Radio Incorporated (ARINC) to exchange messages between an aircraft and ground stations. The voice radio transmissions which was used earlier to exchange information to and from an aircraft was replaced by Very High Frequency (VHF) radio signals. These signals were received and exchanged by a global network of land-based radio stations and satellites. ACARS supported different types of data exchange such as flight path, technical information aircraft systems, and parts, weather information, and communication between the flight crew and ground support stations. But the drawback is it does not provide real-time flight tracking (International Communications Group [ICG], 2006). In 2016, Lufthansa Technik's launched the AVIATAR platform to support the predictive maintenance and other services to airlines, manufacturers, and MROs (Lufthansa Technik, 2018). AVIATAR has recently added three new apps namely, MROradar, AirGlance, and ToolNow digitalize and streamlines reporting which optimizes communication between MROs and airline customers. This cloud-based infrastructure ensures the highest standard of data security for customer data in compliance with European data protection requirements (Lufthansa Technik, 2018).

FAA is attempting to collect and maintain a safety-centric maintenance database (Broderick, 2017). The FAA has also developed programs such as the Aviation Safety Action Program (ASAP), and Aviation Safety Information Analysis and Sharing (ASIAS) program, hoping that these databases will provide additional information which will help to enhance continuous airworthiness (Broderick, 2017). Airlines are also working to collect data to enhance its performance. For example Lufthansa Airlines uses the digital technologies such as Condition Analytics platform (provides actual information about the fleet and predicts outages), DATCOM (data from aircraft equipment life cycles are utilized to optimize the maintenance process), and ADP@WG (Advanced Data Analytics for Proactive Measures) which is based on DATCOM (helps to take proactive measures to avoid delays and cancellation of flights) (Lufthansa Technik, 2018). Apart from legislative requirements, maintenance organizations must also collect data for internal safety and quality programs. If their level of participation increases, it will pave a data-driven pathway to enhance aviation safety.

\section{Recommendations}

Apart from global partnerships, technological advancements, and regulations, data collected from different sources within and across the aircraft maintenance industry will help to proactively identify the factors that cause maintenance errors. The trend analysis of the collected data helps to categorize high-risk areas and take preventive measures. The main purpose of data collection is not only reliability and predictability but also enhancing aviation safety. Moreover, collecting all the information and making the system user-friendly is a 
challenge, but possible. Data is produced 24/7 and the major challenge is its accessibility on time, having the resources to interpret and analyze it, and allowing the organization to make decisions based on these data. If all these can be adopted effectively by both aviation maintenance organizations and airlines operational efficiency could be increased while costs would decrease. For example, let's assume there is a scheduled flight from an Asian country to San Francisco. During flight, the on-board maintenance system indicates that one of the control computers is failing and has to be replaced. This data has to be entered in real-time and the information has to be conveyed to a system that can acquire a flight control computer, and identify an engineer or technician to replace it at the San Francisco Airport upon its estimated time of arrival. If the system has access to the airline's parts inventory to determine if a spare is available, where it is, the cost of the item, and time required for delivery, then it would be easy to make a decision for airlines based on lead-time to delivery, quality, and costs. In short, the entire system has to be automated with data sharing. The entire process of unscheduled maintenance can be streamlined. This type of data sharing will reduce the maintenance costs, enhance the operational efficiency of maintenance organizations and airlines, and ultimately revolutionize the next generation of the aviation industry. This will also reduce human error in all maintenance related processes as the human involvement is reduced. Boeing has recently introduced the Airplane Health Management (AHM) tool which gathers in-flight data and communicates it in real-time to maintenance personnel on the ground through the web portal. This helps to identify frequent errors and trends, which allow the airlines to proactively plan future maintenance (Maggiore, n.d). Several other new tools are being developed by other organizations which will revolutionize the way MROs' are working (Maggiore, n.d). Statistical Analysis for Scheduled Maintenance Optimization (SASMO) tool was developed by Boeing to determine the optimal scheduled maintenance intervals (McLoughlin, Doulatshahi, \& Onorati, 2011). Similarly, ACARS revolutionized the industry by transforming air-to-ground communications from voice-dependent systems to data link. Today, it is the most reliable communications system available in the world. ACARS has tried to maintain the pace in aviation maintenance through the support of different types of data. It can even be optimized to meet the requirements of a specific airline such as hardware requirements, control displays, identification of flight conditions, maintenance and repair plan, engine reports, etc. (ICG, 2006). This type of data analysis will reduce maintenance related costs, enhance safety, and increase the reliability of dispatched aircraft.

\section{Conclusion}

FAA faces significant challenges such as the ability of inspectors to conduct both routine and unannounced inspections and coordinating oversight office inspections for airlines in the foreign repair stations. FAA implemented the Safety 
Assurance System (SAS) in 2015 which is a risk-based oversight system supported by data that helps to standardize the identification of safety risks related to planning and conducting oversight of both domestic and foreign repair stations (GAO, 2016). Though safety implications have been raised against foreign repair stations due to the number of non-certified technicians, any restrictive safety measures and additional inspections towards the part 145 repair stations could affect the maintenance work performed on foreign aircraft within the US, the U.S. companies which operate outside the US, and the U.S. companies that have a stake in repair facilities in foreign countries. International companies also have repair stations within the US. There is no strong evidence to prove that the utilization of foreign repair stations to maintain the U.S. air carrier aircraft has affected its safety (Tang \& Elias, 2012).

Boeing has recently developed an optimized maintenance program that is receptive to the necessities of an airline operator (Boeing, 2016). This program performs the custom statistical analysis of maintenance data exclusively of the airline's data (Grokhovskaya, 2018b). This cost-effective approach will minimize the ever-increasing maintenance costs and the operational disruptions (Boeing, 2016). Moreover, most of the current projects of Airlines, MROs, Engine, and Airframe manufacturers prove that if all these stakeholders work collaboratively and utilize the maintenance data effectively it will help to increase the operational efficiency and reduce the costs.

The FAA should mandate that all aviation maintenance organizations implement SMS programs. As human factor issues play a significant role in maintenance errors, it is more efficient to integrate these elements into existing SMS programs for aviation maintenance. A new safety reporting system, such as the REPAIRER reporting system (Miller, 2016), should be considered for outsourcing maintenance organizations. This would be an excellent option as it adheres to the SMS criteria of FAA and ICAO. Additionally, if a holistic maintenance approach is adopted by all the stakeholders in aircraft maintenance, it will help to minimize the inevitable maintenance downtime during an aircraft's service life, ensuring airworthiness and ultimately safety. 


\section{References}

Adams, C. (2017). Big challenges, big opportunities. Aviation Maintenance. Retrieved from https://www.avm-mag.com/commercia-pure-mropuremor-is-primed-for-growth-but-faces-more-than-the-usual-challenges/

Al-Kaabi, H., Potter, A. T., \& Naim, M. M. (2007). An outsourcing decision model for airlines' MRO activities. Journal of Quality Maintenance Engineering, 13(3), 217-227. https://doi.org/10.1108/13552510710780258

Baker, B. J. (2001). Identifying the probability of an accident occurring with suspected unapproved parts as a contributing factor. Journal of Aviation/Aerospace Education \& Research, 10(2), 15-29. Retrieved from https://commons.erau.edu/jaaer/vol10/iss $2 / 5 /$

Boeing. (2016). Business consulting: Optimized maintenance programs [pdf]. Retrieved from https://www.boeing.com/resources/boeingdotcom/ commercial/services/assets/brochure/optimized-maintenanceprograms.pdf

Cooper, T., Smiley, J., Porter, C., \& Precourt, C. (2018). Global fleet MRO market forecast commentary 2018-2028. Retrieved from http://www.oliverwyman.com/content/dam/oliver-wyman/v2/ publications/2018/January/2018-2028_Global_Fleet_MRO_Market_ Forecast_Commentary_Public_Final_web.pdf

Cooper, T., Reagan, I., Porter, C., \& Precourt, C. (2019). Global fleet MRO market forecast commentary 2019-2029. Retrieved from https://www.oliverwyman.com/content/dam/oliver-wyman/v2/ publications/2019/ January/global-fleet-mro-market-forecast-commentary2019-2029.pdf

Crawley, J. (2010, August 26). Record \$24.2 million fine proposed for American Airlines. Business News. Retrieved from https://www.reuters.com/article/ us-amr-fine/record-24-2-million-fine-proposed-for-american-airlinesidUSTRE67P3TU20100826

Czepiel, E. (2003). Practices and perspectives in outsourcing aircraft maintenance (DOT/FAA/AR-02/122). Retrieved from https://www.faa.gov/about/initiatives/maintenance_hf/library/documents/ media/human_factors_maintenance/ar02-122.pdf

Doan, C. (2015, 13th October 2015). Turbulence ahead disengage the autopilot. 2015-2025 Global Fleet \& MRO Market Forecast. In Proceedings of the symposium conducted at the Aviation Week MRO, Europe. Retrieved from http://www.oliverwyman.com/content/dam/oliver-wyman/global/ en/2015/oct/2015_2025_ MRO_Forecast\%20_Trends_MRO_Europe_Presentation_20151013.pdf

Federal Aviation Administration. (2015). Safety management systems for aviation service providers (AC 120-92B). Retrieved from 
https://www.faa.gov/documentLibrary/media/Advisory_Circular/AC_12092B.pdf

Federal Aviation Administration. (2016). Air carrier maintenance programs (AC 120-16G). Retrieved from https://www.faa.gov/documentLibrary/media/ Advisory_Circular/AC_120-16G.pdf

Gallagher, S. (2018, April 19). Flight 1380 - Southwest Airlines protested airworthiness directive designed to prevent engine failures. Arstechnica. Retrieved from https://arstechnica.com/tech-policy/2018/04/southwestairlines-protested-airworthiness-directive-designed-to-prevent-enginefailures/

General Accounting Office. (1997). FAA oversight of repair stations needs improvement (GAO/RCED 98-21). Retrieved from http://www.gao.gov/ archive/1998/rc98021.pdf

Government Accountability Office. (2016). Aviation safety - FAA's risk-based oversight for repair stations could benefit from additional airline data and performance metrics (GAO-16-679). Retrieved from https://www.gao.gov/ assets/680/678837.pdf

Grokhovskaya, V. (2018a, February 23). 5 MRO supply chain challenges aviation companies need to prepare for. Supply Chain Management - The Network Effect. Retrieved from https://supplychainbeyond.com/5-mrosupply-chain-challenges-in-aviation/

Grokhovskaya, V. (2018b, March 28). Maintaining airworthiness with a strong aircraft maintenance program. Intelligent Aerospace, Global Aerospace Technology Network. Retrieved from https://www.intelligentaerospace.com/articles/2018/03/maintaining-airworthiness-with-a-strongaircraft-maintenance-program.html

Helms, M. M., \& Nixon, J. (2010). Exploring SWOT analysis - where are we now?: A review of academic research from the last decade. Journal of Strategy and Management, 3(3), 215-251.

International Air Transport Association. (2011, January). Airline maintenance costs executive commentary. Retrieved from http://www.dea.univr.it/ documenti/Avviso/all/all698615.pdf

International Civil Aviation Organization. (2013). Safety management manual (SMM) (Doc 9859. AN/474, 3rd Ed.). Retrieved from https://www.icao.int/safety/SafetyManagement/Documents/Doc.9859.3rd $\% 20$ Edition.alltext.en.pdf

International Civil Aviation Organization. (2016). 2017-2019 global aviation safety plan (Doc 10004). Retrieved from https://www.icao.int/Meetings/ a39/Documents/GASP.pdf

International Communications Group. (2006). Introduction to ACARS messaging services - As implemented via Iridium satellite link (Application Note ICS- 
200-01). Retrieved from https://www.icao.int/safety/acp/inactive\%

20working20groups\%20library/acp-wg-m-iridium-7/ird-swg07wp08\%20-\%20acars\%20app\%20note.pdf

Japan Transport Safety Board. (2009). Aircraft accident investigation report China Airlines B18616 (AA2009-7). Retrieved from http://www.mlit.go.jp/jtsb/eng-air_report/B18616.pdf

Josephs, L. (2018, May 9). Watchdog probes FAA's review of aircraft maintenance at American Airlines and Allegiant Air. CNBC. Retrieved from https://www.cnbc.com/2018/05/09/faa-faces-audit-overmaintenance-oversight-at-american-and-allegiant.html

Lash, N., Levesque, W. R., \& Cormier, A. (2016, November 2). Breakdown at 30,000 Feet. Tampa Bay Times. Retrieved from http://www.tampabay.com/projects/2016/investigations/allegiantair/mechanical-breakdowns/

Levin, A., \& Suhartono, H. (2019, April 2). Faulty 737 sensor in Lion Air crash linked to U.S. repairer. Bloomberg. Retrieved from https://www.bloomberg.com/news/articles/2019-04-02/faulty-737-sensorfrom-lion-air-crash-linked-to-u-s-repair-shop

Lufthansa Technik. (2018, April 10). One year after introduction-AVIATAR on track [Press release]. Retrieved from https://www.lufthansa-technik.com/ press-releases-content/-/asset_publisher/9Mf5/content/press-releaseaviatar-one-year-after-the-launch/10165

Maggiore, J. B. (n.d). Remote management of real-time airplane data. Aero. Retrieved from https://www.boeing.com/commercial/aeromagazine/ articles/qtr_3_07/AERO_Q307_article4.pdf

McFadden, M., \& Worrells, D. S. (2012). Global outsourcing of aircraft maintenance. Journal of Aviation Technology and Engineering, 1(2), 6373. https://doi.org/10.5703/1288284314659

McLoughlin, B., Doulatshahi, F., \& Onorati, J. (2011). Improving maintenance programs through statistical analysis. Boeing Aero Magazine, 3(11). Retrieved from https://www.boeing.com/commercial/aeromagazine/ articles/2011_q3/pdfs/AERO_2011_Q3_article3.pdf

Miller, M. D. (2016). The repairer reporting system strategy for aviation maintenance: Integrating human factors and risk management into aviation maintenance for SMS compliance. Paper presented at the Presentation to FAA Aviation Maintenance Mega Conference, Honolulu. National Transportation Safety Board. (1996). Uncontained engine failure/fire ValueJet Airlines flight 597Douglas DC-9-32, N908VJ, Atlanta, Georgia, June 8, 1995 (NTSB/AAR-96/03). Retrieved from https://www.ntsb.gov/ investigations/AccidentReports/Reports/AAR9603.pdf 
Office of Inspector General. (2009). Actions needed to improve safety oversight and security at aircraft repair stations (CC-2010-005). Retrieved from https://www.oig.dot.gov/sites/default/files/H_Hmlnd_Sub_Hrg_For_Rep_ Stations_11.18.09.pdf

Philips, M. (2011). Why do airlines always lose money? Hint: It's not due to taxes or fuel costs [Blog post]. Retrieved from http://freakonomics.com/ 2011/06/24/why-do-airlines-always-lose-money-hint-its-not-due-to-taxesor-fuel-costs/

Regattieri, A., Giazzi, A., Gamberi, M., \& Gamberini, R. (2015). An innovative method to optimize the maintenance policies in an aircraft: General framework and case study. Journal of Air Transportation Management, 44-45, 8-20. https://doi.org/10.1016/j.jairtraman.2015.02.001

Ridge Global. (2018). Risks associated with foreign repair stations. Retrieved from http://www.twu.org/wp-content/uploads/2018/05/Risks-Associatedwith-Foreign-Repair-Stations.pdf

Rothman, A. (2011, November 25). Air France A340 flew with missing screws after maintenance visit. China Aviation Daily. Retrieved from http://www.chinaaviationdaily.com/news/16/16749.html

Steele, J. B. (2015). The disturbing truth about how airplanes are maintained today. Vanity Fair. Retrieved from https://www.vanityfair.com/news/ 2015/11/airplane-maintenance-disturbing-truth

Tang, R., \& Elias, B. (2012). Offshoring of airline maintenance: Implications for domestic jobs and aviation safety. Congressional Research Service, 1-30. Retrieved from http://amfa32.com/Legislative/CRS\%20Report\%20$\% 20$ Offshoring\%20Airline\% 20 Maintenance.pdf

Zwerdling, D. (2009). Flight mechanics:The business of airline repairs: To cut costs, airlines send repairs abroad [Radio series]. Retrieved from https://www.npr.org/templates/story/story.php?storyId=113877784 